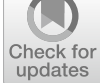

Check for
updates

Cite as

Nano-Micro Lett.

(2021) $13: 169$

Received: 22 May 2021

Accepted: 11 July 2021

Published online: 6 August 2021

(C) The Author(s) 2021

\section{A Special Additive Enables All Cations and Anions Passivation for Stable Perovskite Solar Cells with Efficiency over 23\%}

\author{
Wenjing Zhao ${ }^{1}$, Jie Xu ${ }^{1}$, Kun $\mathrm{He}^{1}$, Yuan $\mathrm{Cai}^{1}$, Yu Han ${ }^{1}$, Shaomin Yang ${ }^{1}$, Sheng Zhan ${ }^{1}$, \\ Dapeng Wang ${ }^{1}$, Zhike Liu ${ }^{1}$, Shengzhong Liu ${ }^{1,2} \bowtie$
}

\title{
HIGHLIGHTS
}

- A special additive-(benzylamine)trifluoroboron (BBF) is applied to improve the quality of $\mathrm{FAMAPbI}_{3}$ perovskite.

- BBF concurrently passivates cationic and anionic perovskite defects.

- The perovskite solar cell with BBF shows a high power conversion efficiency of $23.24 \%$ and an excellent stability.

ABSTRACT Passivating undercoordinated ions is an effective way to reduce the defect densities at the surface and grain boundaries (GBs) of perovskite materials for enhanced photovoltaic performance and stability of perovskite solar cells (PSCs). Here, (BBF) complex is chosen as a multifunctional additive, which contains both $\mathrm{C}_{7} \mathrm{H}_{9} \mathrm{~N}$ and $\mathrm{BF}_{3}$ groups working as Lewis base and Lewis acid, respectively, can bond with $\mathrm{Pb}^{2+}$ / $\mathrm{I}^{-}$and $\mathrm{FA}^{+}$on the surface and in the GBs in the perovskite film, affording passivation of both cation and anion defects. The synergistic effect of the $\mathrm{C}_{7} \mathrm{H}_{9} \mathrm{~N}$ and $\mathrm{BF}_{3}$ complex slows the crystallization during the perovskite film deposition to improve the crystalline quality, which reduces the trap density and the recombination in the perovskite film to suppress nonradiative recombination loss and minimizes moisture permeation to improve the stability of the perovskite material. Meanwhile, such an additive improves the energy-level alignment between the valence band

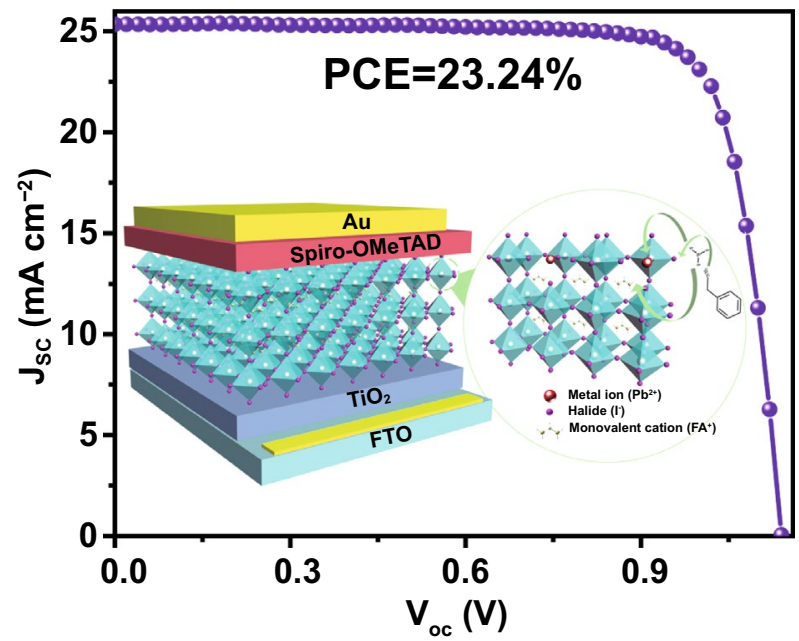
of the perovskite and the highest occupied molecular orbital of the hole-transporting material, Spiro-OMeTAD. Consequently, our work achieves power conversion efficiency of $23.24 \%$, accompanied by enhanced stability under ambient conditions and light illumination and opens a new avenue for improving the performance of PSCs through the use of a multifunctional complex.

KEYWORDS Additives; Simultaneous passivation; Combined effects; High efficiency; Perovskite solar cells

Zhike Liu, zhike2015@ snnu.edu.cn; Shengzhong Liu, szliu@dicp.ac.cn

1 Key Laboratory of Applied Surface and Colloid Chemistry, Ministry of Education, Shaanxi Key Laboratory for Advanced Energy Devices, Shaanxi Engineering Lab for Advanced Energy Technology, School of Materials Science \& Engineering, Shaanxi Normal University, Xi'an 710119, People's Republic of China

2 Dalian National Laboratory for Clean Energy, iChEM, Dalian Institute of Chemical Physics, Chinese Academy of Sciences, Dalian 116023 , People's Republic of China 


\section{Introduction}

Organic-inorganic hybrid perovskite solar cells (PSCs) have gained enormous attention during the past decade due to their superb photovoltaic properties, low-cost manufacturing technologies, and unprecedented rise in power conversion efficiencies (PCEs) [1, 2]. However, the certified champion PCE $(25.5 \%)$ of the PSCs is still far from their theoretical value predicted from the Shockley-Queisser (S-Q) theory $(\sim 31 \%)$, mainly due to the open-circuit voltage $\left(V_{o c}\right)$ loss from nonradiative recombination [3]. Unlike the traditional robust perovskite oxides (e.g., $\mathrm{CaTiO}_{3}$ ), the frail Coulombic interaction and weak ionic bonding cause the vulnerable ions to escape or reorganize in the perovskite film [4, 5], which generates a considerable number of deep defects serving as nonradiative recombination centers and thus results in $V_{o c}$ and PCE loss in the PSCs. In addition, these deep defects, such as vacancies and undercoordinated ions formed at the surface and GBs of the perovskite, impair the stability of the PSCs $[6,7]$.

In FAMAPbI ${ }_{3}$ ([FA] formamidinium $\mathrm{CH}\left(\mathrm{NH}_{2}\right)_{2}$, [MA] methylammonium $\mathrm{CH}_{3} \mathrm{NH}_{3}$ ) hybrid perovskite, the larger $\mathrm{FA}^{+}$cation has a smaller dipole moment and a weaker interaction with the $\left[\mathrm{PbI}_{6}\right]^{2-}$ octahedral, which results in the formation of $\mathrm{Pb}$-I antisite defects in at the $\mathrm{FA}^{+}$-dominant perovskite surface and causes deep-level defects such as $\mathrm{Pb}$ clusters (i.e., $\mathrm{Pb}^{2+}$ dimers) $[8,9]$. Meanwhile, the volatile component of $\mathrm{MA}^{+}$cations tends to escape from $\mathrm{FAMAPbI}_{3}$ perovskite under thermal stress, which results in the formation of undercoordinated $\mathrm{Pb}^{2+}$ deep-level defects that serving as electron traps [10]. A great many works have been found that these $\mathrm{Pb}$-related defects (e.g., $\mathrm{Pb}$ clusters and uncoordi-

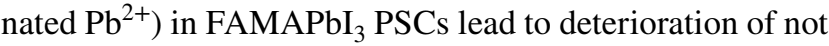
only the device PCE but also the stability [11]. Meanwhile, in $\mathrm{FAMAPbI}_{3}$ perovskite, due to the large size of the cations, shallow iodine interstitial and vacancy defects can be generated unintentionally during thermal annealing or device measurement processes, which can lower activation energy barrier for transformation from the $\alpha$ phase to $\delta$ phase [12].

Recently, various molecules have been developed as additives to heal/reduce $\mathrm{FA}^{+} / \mathrm{MA}^{+} / \mathrm{I}^{-}$vacancy or Pb-related defects for suppressing the nonradiative recombination loss in FAMAPbI ${ }_{3}$ PSCs, eventually enhancing the $V_{o c}, \mathrm{PCE}$ and stability $[13,14]$. However, most of them are supposed to play a single role, and can only passivate one or two charged defects in $\mathrm{FAMAPbI}_{3}$ perovskite [15]. There are very few molecules that can passivate both all the $\mathrm{FA}^{+} / \mathrm{MA}^{+} / \mathrm{Pb}^{2+}$ cations and $\mathrm{I}^{-}$anions in $\mathrm{FAMAPbI}_{3}$. Therefore, it is necessary to develop a multifunctional molecule that can passivate all the charged defects in dual-cation perovskite to further enhance the device performance.

Here, we firstly introduced a multifunctional additive (Benzylamine)Trifluoroboron (BBF) that contains both $\mathrm{C}_{7} \mathrm{H}_{9} \mathrm{~N}$ and $\mathrm{BF}_{3}$ groups into perovskite precursor because of the following advantages: (1) The new additive (BBF) can retard the crystallization process of the perovskite film to improve the film quality. (2) BBF behaves both as the a Lewis acid (electron acceptor) and the a Lewis base (electron donor) to simultaneously bond with $\mathrm{FA}^{+} / \mathrm{MA}^{+} / \mathrm{Pb}^{2+}$ cations and $\mathrm{I}^{-}$anions on the surface and at the grain boundaries (GBs) of perovskite films, which can effectively heal/reduce $\mathrm{FA}^{+} / \mathrm{MA}^{+}$vacancy and $\mathrm{Pb}$-related defects and prevent the movement of $\mathrm{I}^{-}$ions. (3) A surface gradient distribution of BBF can modulate the surface electronic properties of the perovskite, leading to a better match of energy-level alignment between the perovskite and Spiro-OMeTAD. (4) $\mathrm{BF}_{3}$ in BBF can increase the hydrophobicity of the perovskite surface to further improve the stability of the PSCs. The combination of the above effects resulted in suppressed nonradiative recombination loss in the PSCs and a significantly increased PCE from 21.60 to $23.24 \%$. Additionally, the device with BBF exhibited a smaller hysteresis and improved ambient and light illumination stability.

\section{Experimental Section}

\subsection{Materials}

Unless otherwise specified, all of the materials were purchased from Xi' an Polymer Light Technology Corp. (Benzylamine)Trifluoroboron was purchased from Accela ChemBio Co. Ltd. N,N-dimethylformamide (DMF) and dimethylsulfoxide (DMSO) were purchased from Shanghai Aladdin Biochemical Technology Co. Ltd.

\subsection{Solar Cell Fabrication}

FTO glass was first cleaned by ultrasonic for 30 min with glass cleaner (water to glass cleaner ratio is 100: 1), and then 
cleaned by ultrasonic for two times with ultra-pure water for $30 \mathrm{~min}$ each time. Before deposition of $40 \mathrm{~nm} \mathrm{TiO}_{2}$ on a clean FTO glass substrate by chemical bath deposition, in accordance with our previously reported method [16], the glass was air-dried and UV treated for $15 \mathrm{~min}$. The $1.0 \mathrm{M}$ $\mathrm{FA}_{0.85} \mathrm{MA}_{0.15} \mathrm{PbI}_{3}$ precursor solution was prepared by mixing FAI, MAI, $\mathrm{PbI}_{2}$ in mixed DMF and DMSO with ratio 4:1. To prepare the $\mathrm{FA}_{0.85} \mathrm{MA}_{0.15} \mathrm{PbI}_{3}$ film with $\mathrm{BBF}$ additive, the different $\operatorname{BBF}(0.5,1.0,1.5,2.0 \mathrm{mg})$ was added into $1 \mathrm{~mL}$ perovskite precursor solution. Mixture was stirred at room temperature before using. After annealing $\mathrm{TiO}_{2}$ on a hot platform at $200{ }^{\circ} \mathrm{C}$ for $30 \mathrm{~min}$ and UV for $10 \mathrm{~min}$, $50 \mu \mathrm{L}$ of perovskite precursor solution was spin-coated on the $\mathrm{TiO}_{2}$ by two-step anti-solvent spin coating method (spun at $1000 \mathrm{rpm}$ for $10 \mathrm{~s}$ and then $4000 \mathrm{rpm}$ for $45 \mathrm{~s}$ ), and $200 \mu \mathrm{L}$ of chlorobenzene was dropped at the spin coating for $20 \mathrm{~s}$, followed by thermal annealing at $150{ }^{\circ} \mathrm{C}$ for $30 \mathrm{~min}$ to obtain dark films. The Spiro-OMeTAD $\left(90 \mathrm{mg} \mathrm{mL}^{-1}\right)$ mixed with 4-tert-butylpyridine $\left(36 \mu \mathrm{L} \mathrm{mL}^{-1}\right)$ and $22 \mu \mathrm{L} \mathrm{Li-TFSI}$ (520 mg mL $\mathrm{mL}^{-1}$ in acetonitrile) was spun at $3000 \mathrm{rpm}$ for $30 \mathrm{~s}$ to prepare hole-transport layer on perovskite surface to obtain $\mathrm{FTO} / \mathrm{TiO}_{2} /$ perovskite/Spiro-OMeTAD architecture, finally, the gold electrode $(\sim 80 \mathrm{~nm})$ was thermally deposited on Spiro-OMeTAD, the device active area was defined as $0.09 \mathrm{~cm}^{2}$.

\subsection{Device Characterization}

The $J$ - $V$ curves were obtained by a Keithley 2400 source under the AM $1.5 \mathrm{G}$ irradiation $\left(100 \mathrm{~mW} \mathrm{~cm}^{-2}\right)$. All devices were tested from 2 to $-0.1 \mathrm{~V}$ at a rate of $10 \mathrm{mV} \mathrm{s}^{-1}$. EQE spectra was recorded using a Q Test Station 500TI system (Crowntech, Inc. USA). XRD patterns were taken with D/ MAX 2400 diffractometer. XPS and UPS were analyzed using a photoelectron spectrometer (ESCALAB250Xi, Thermo Fisher Scientific), UV/Vis NIR spectrophotometer was used to obtain absorption spectra of perovskite films (Per-kinElmer, Lambda 950), PL and TRPL spectra (excitation at $510 \mathrm{~nm}$ ) were measured using a FLS980 spectrometer and PicoQuant FluoQuant 300, respectively. Surface and cross-sectional SEM images were perform by a fieldemission SEM (HITACHI, SU-8020), AFM images were produced by Veeco Nano Scope IV with a silicon cantilever, FTIR spectra were investigated with a Bruker Vertex 70. For NMR measurements, JNM-ECZ400S/L1 with a frequency of $400 \mathrm{MHz}$ were used, FAI, MAI, $\mathrm{PbI}_{2}$, and BBF were dissolve in d6-DMSO. ToF-SIMS characterization was detected by a ION TOF-SIMS 5. Water contact angles were tested using a DataPhysics OCA 20.

\section{Results and Discussion}

\subsection{Effect of BBF on Crystallization Process of Perovskite}

Figure 1a presents a comparison of photographs of perovskite films with and without BBF additive. Both of the freshly spincoated films on FTO are transparent, and after annealing for $10 \mathrm{~s}$, the part of the control film begins to turn dark brown, and after $60 \mathrm{~s}$, the whole control film turns dark brown. Compared to the control film, the BBF- modified film obviously takes a long time to finish the same crystallization process, and after annealing for $60 \mathrm{~s}$, the film with BBF shows light gray and needs to be annealed at $100{ }^{\circ} \mathrm{C}$ to turn black. For the sake of investigating the role of $\mathrm{BBF}$ additive in perovskite growth, the perovskite precursors with and without BBF are annealed at different temperature gradients. As shown in the Fourier transform infrared (FTIR) spectra in Fig. 1b, the stronger absorption peak at $3431 \mathrm{~cm}^{-1}$ is attributed to the $\mathrm{N}-\mathrm{H}$ stretching vibration in FA/MA, and the spectral characteristic between 1200 and $1600 \mathrm{~cm}^{-1}$ is assigned to the stretching vibration absorption of $\mathrm{C}=\mathrm{C}$ in the benzene ring. With the increase of annealing temperature, the $\mathrm{N}-\mathrm{H}$ stretching vibration shifts to lower wavenumber, and the intensity of the above peaks is strengthened, indicating that there is a strong interaction between the BBF and FAI, which is due to the formation of hydrogen bonds $(\mathrm{N}-\mathrm{H} \cdots \mathrm{F})$ between the FA/MA and F species. The FTIR spectra of the precursor film containing only $\mathrm{BBF}$ and $\mathrm{PbI}_{2}$ is also measured and displayed in Fig. 1c. The spectrum exhibits the characteristic peaks of B-N $\left(\sim 1380 \mathrm{~cm}^{-1}\right)$, B-F $(\sim 1445$ and $\left.1498 \mathrm{~cm}^{-1}\right), \mathrm{C}=\mathrm{C}$ from the benzene ring $\left(\sim 1630 \mathrm{~cm}^{-1}\right), \mathrm{C}-\mathrm{H}$ $\left(\sim 3005\right.$ and $\left.2915 \mathrm{~cm}^{-1}\right)$, and $\mathrm{N}-\mathrm{H}\left(\sim 3441 \mathrm{~cm}^{-1}\right)$. When the film is annealed at $60{ }^{\circ} \mathrm{C}$ for $60 \mathrm{~s}$, the $\mathrm{S}=\mathrm{O}$ peak from DMSO disappears, and the $\mathrm{B}-\mathrm{F}$ and $\mathrm{B}-\mathrm{N}$ bonds move in the direction of lower wavenumber, manifesting that the formation of ionic bonds between $\mathrm{F}$ and $\mathrm{Pb}$ impaired the interaction between $\mathrm{B}$ and F. According to the FTIR results, BBF can simultaneously bond with $\mathrm{FA}^{+}, \mathrm{MA}^{+}$, and $\mathrm{Pb}^{2+}$ cations to form some new adducts, such as BBF-FAI, BBF-MAI and BBF-PbI ${ }_{2}$, and the large steric hindrance of these adducts will inhibit the direct 
(a)
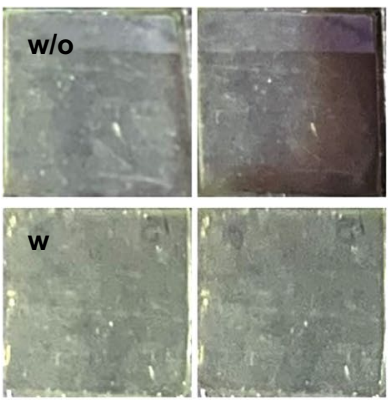

$0 \mathrm{~s}$

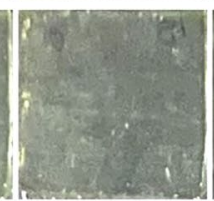

$10 \mathrm{~s}$
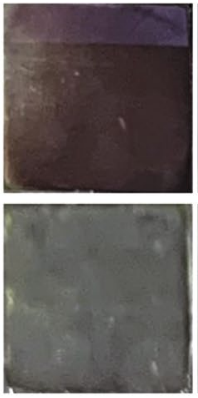

$30 \mathrm{~s}$
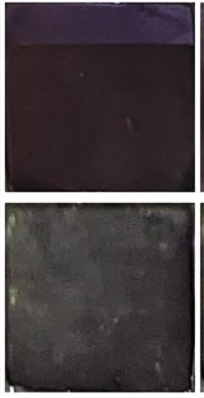

$60 \mathrm{~s}$
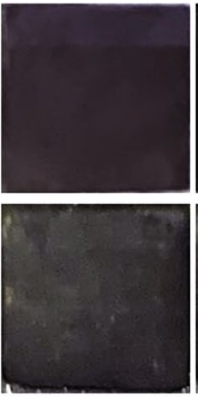

$90 \mathrm{~s}$
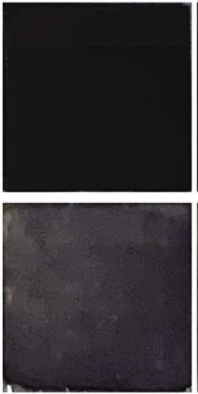

$100 \mathrm{~s}$
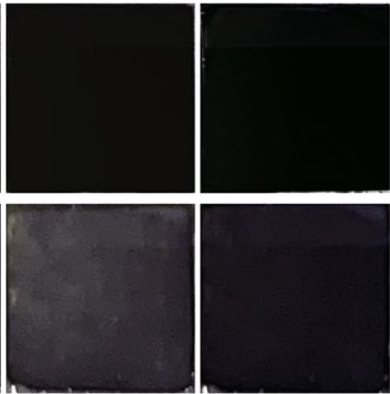

110 s

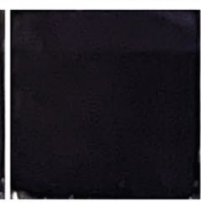

$120 \mathrm{~s}$ $60^{\circ} \mathrm{C}$

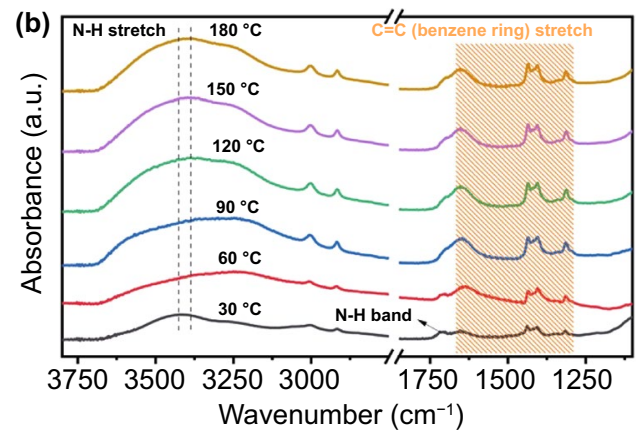

$100{ }^{\circ} \mathrm{C}$
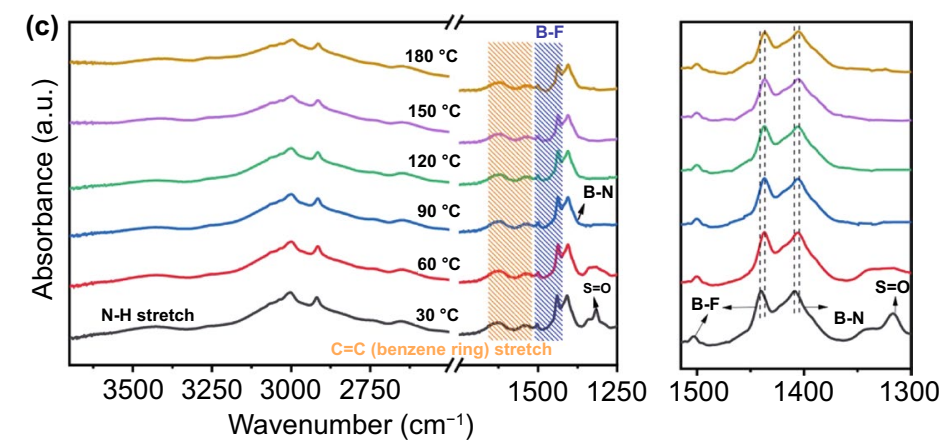

Fig. 1 a Photographs of perovskite precursor films without and with $1.5 \mathrm{mg} \mathrm{mL}-1 \mathrm{BBF}$ additive annealed at $60{ }^{\circ} \mathrm{C} / 100{ }^{\circ} \mathrm{C}$ for different times. FTIR spectra of $\mathbf{b}$ the FAI precursor film with $\mathrm{BBF}$ additive and $\mathbf{c}$ the $\mathrm{PbI}_{2}$ precursor film with $\mathrm{BBF}$ additive annealed for $60 \mathrm{~s}$ at different temperatures in ambient air (RH: $30 \%$, T: $25^{\circ} \mathrm{C}$ )

reaction between MAI/FAI and $\mathrm{PbI}_{2}$ [17]. Therefore, during the Ostwald ripening process of the perovskite precursor film with BBF $[18,19]$, BBF will reduce the amount of perovskite nucleation, slow the crystallization, and increase the perovskite grain size to improve the film quality. When the film is annealed at $180{ }^{\circ} \mathrm{C}, \mathrm{B}-\mathrm{F}$ and $\mathrm{C}=\mathrm{C}$ peaks still exist in the FTIR spectrum, which verifies the presence of $\mathrm{BBF}$ molecules in the final perovskite film, the thermogravimetric analysis in Fig. S1 and the X-ray photoelectron spectroscopy (XPS) data in Fig. S2 also support this conclusion. The remaining BBF molecules form ionic bonds and hydrogen bonds with the uncoordinated metal and organic cation defects, and these bonds can passivate the defects on the surface and GBs of the perovskite films [20].

\subsection{Interaction between BBF and MAI/FAI}

In order to further elucidate the interaction between BBF and MAI/FAI in perovskite, a series of characterizations such as XPS, FTIR, and Nuclear magnetic resonance (NMR) are carried out. As shown in Fig. 2a, b, the $\mathrm{N}$ 1s signal at $402.15 \mathrm{eV}$ is detected for the pristine BBF film, and the typical bonds of $\mathrm{C}-\mathrm{N}$ and $\mathrm{C}=\mathrm{N}$ are detected at 400.09 and $401.08 \mathrm{eV}$ corresponding to $\mathrm{MA}^{+}$and $\mathrm{FA}^{+}$cations, respectively. In the $\mathrm{N}$ 1s XPS spectra of the composites $(\mathrm{BBF}+\mathrm{MAI}$ or $\mathrm{BBF}+\mathrm{FAI})$, the feature peaks corresponding to $\mathrm{C}-\mathrm{N}$ and $\mathrm{C}=\mathrm{N}$ bonds shrink and shift to higher binding energies compared with pure MAI and FAI, which is due to the formation of hydrogen bonds $(\mathrm{N}-\mathrm{H} \cdots \mathrm{F})$ between the MAI/FAI and F from BBF. This interaction is also confirmed by the FTIR spectra (Fig. 2c, d), where compared to the pure FA/MA, the $\mathrm{N}-\mathrm{H}$ vibration in FAI-BBF/MAI-BBF composite shows a shift toward lower wavenumber [21]. The liquid-state ${ }^{1} \mathrm{H},{ }^{19} \mathrm{~F}$, and ${ }^{11} \mathrm{~B}$ NMR measurements also confirm the formation of hydrogen bonds between the $\mathrm{F}$ in $\mathrm{BBF}$ and MAI/FAI. Figures 2e-h and S2, S3 make clear that the characteristic ${ }^{1} \mathrm{H}\left(\mathrm{H}_{\mathrm{d}}\right.$ and $\mathrm{H}_{\mathrm{e}}$ close to $\mathrm{N}$ that interact with ${ }^{19} \mathrm{~F}$ ) NMR peaks in BBF show an obvious shift to higher $\delta$ value and broadening when mixed with FAI/MAI, which suggests that the interaction between the $\mathrm{N}$ and $\mathrm{F}$ in $\mathrm{BBF}$ is attenuated due to the formation of hydrogen bonds between 

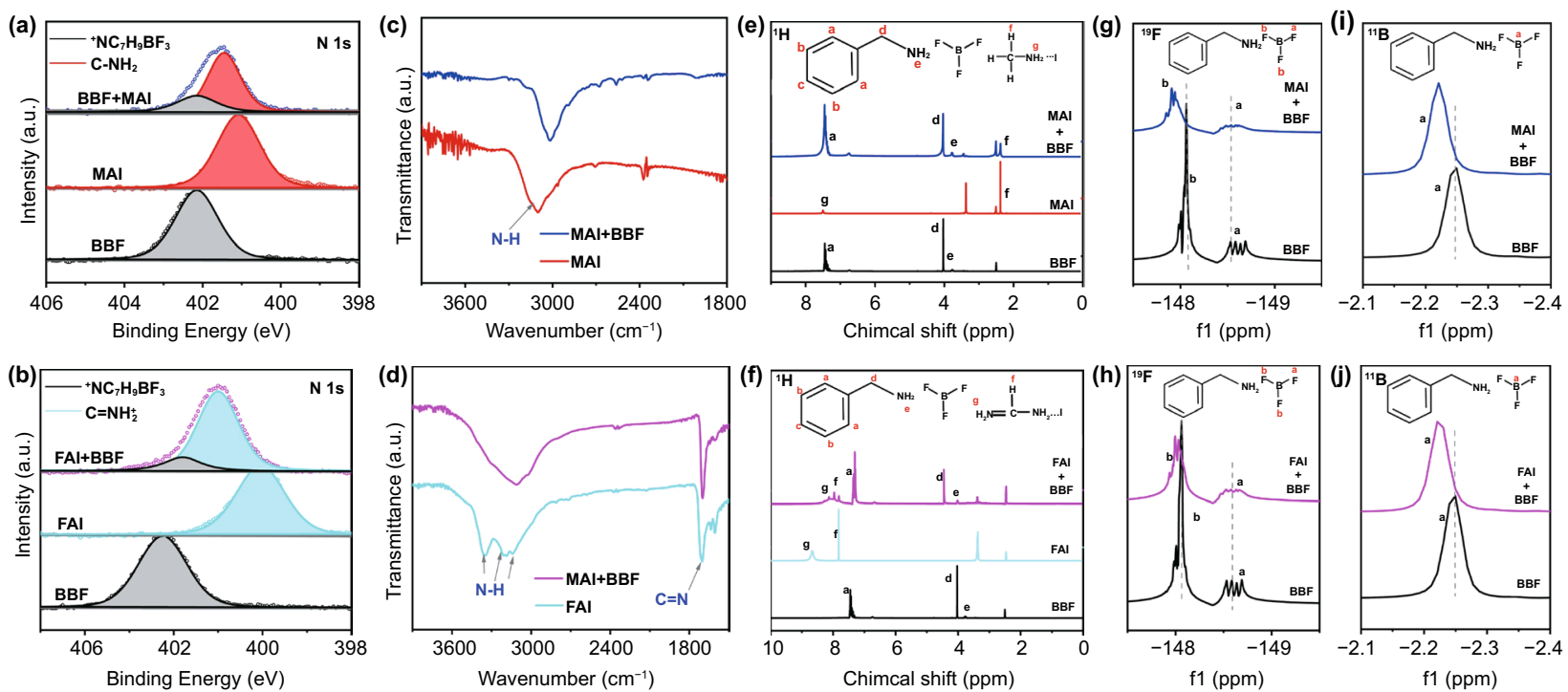

Fig. $2 \mathrm{~N}$ 1s XPS of a BBF, MAI and BBF+MAI and b BBF, FAI and BBF+FAI. FTIR of $\mathbf{c}$ MAI, MAI+BBF and d FAI, FAI+BBF. ${ }^{1} \mathrm{H}$ $\mathrm{NMR}$ of $\mathbf{e} \mathrm{BBF}, \mathrm{MAI}$ and $\mathrm{BBF}+\mathrm{MAI}$ and $\mathbf{f} \mathrm{BBF}, \mathrm{FAI}$ and $\mathrm{BBF}+\mathrm{FAI},{ }^{19} \mathrm{~F} \mathrm{NMR}$ of $\mathbf{g} \mathrm{BBF}, \mathrm{MAI}+\mathrm{BBF}$ and $\mathbf{h} \mathrm{BBF}, \mathrm{FAI}+\mathrm{BBF},{ }^{11} \mathrm{~B} \mathrm{NMR}$ of $\mathbf{i}$ $\mathrm{BBF}, \mathrm{MAI}+\mathrm{BBF}$ and $\mathbf{j} \mathrm{BBF}, \mathrm{FAI}+\mathrm{BBF}$

$\mathrm{N}$ in FAI/MAI and $\mathrm{F}$ in BBF [22, 23]. The newly formed hydrogen bonds between $\mathrm{BBF}$ and FAI/MAI can weaken the shielding of protons on $\mathrm{H}_{\mathrm{d}} / \mathrm{H}_{\mathrm{e}}$ in BBF and result in shifting of the resonance to a lower magnetic field, corresponding to higher $\delta$ value [24].

\subsection{Interaction between $\mathrm{BBF}$ and $\mathrm{PbI}_{2}$}

For hybrid $\mathrm{FAMAPbI}_{3}$ perovskite, uncoordinated metal cations at the crystal surface are unstable in the presence of oxygen and water and will form lead oxide and hydroxide species when exposed to air [25]. Therefore, the passivation on the metal cations in hybrid perovskite is also important. Compared with pure $\mathrm{PbI}_{2}$, the binding energies (BEs) of $\mathrm{Pb} 4 \mathrm{f}$ and I $3 \mathrm{~d}$ XPS spectra are both shifted to lower energy by $\sim 0.5 \mathrm{eV}$ in the $\mathrm{PbI}_{2}$-BBF composite (Figs. 3a and $\mathrm{S} 2$ ). The BE shift of $\mathrm{Pb} 4 \mathrm{f}$ originates from the ionic bond $(\mathrm{Pb}-\mathrm{F})$ interaction between $\mathrm{Pb}^{2+}$ and the $\mathrm{BBF}$, meaning that the $\mathrm{BBF}$ can passivate the uncoordinated $\mathrm{Pb}^{2+}$, thereby reducing the formation of metallic lead. The BE shift of I $3 \mathrm{~d}$ may be due to the hydrogen bond $\left(\mathrm{N}-\mathrm{H} \cdots \mathrm{I}\right.$ ) between $\mathrm{N}-\mathrm{H}$ in $\mathrm{BBF}$ and iodide in $\mathrm{PbI}_{2}$ [26]. Therefore, BBF modification can not only passive the $\mathrm{Pb}$ and I defects but also influence the band structure of the perovskite because the $\mathrm{Pb} 4 \mathrm{f}$ and I $3 \mathrm{~d}$ core levels are closer to the Fermi level of the perovskite [27]. The interaction between $\mathrm{PbI}_{2}$ and BBF is further confirmed by FTIR spectra and NMR. As shown in Fig. 3b, compared with pure $\mathrm{BBF}$, the $\mathrm{N}-\mathrm{H}$ and $\mathrm{B}-\mathrm{F}$ stretching vibrations in $\mathrm{BBF}$ show an obvious shift to lower wavenumber in $\mathrm{PbI}_{2}-\mathrm{BBF}$ composite, providing evidence to confirm the interactions between $\mathrm{BBF}$ and $\mathrm{PbI}_{2}$ observed in the XPS spectra [28]. Figure $3 \mathrm{c}$ shows the ${ }^{1} \mathrm{H},{ }^{19} \mathrm{~F}$, and ${ }^{11} \mathrm{~B}$ NMR patterns of the pure $\mathrm{BBF}$ and $\mathrm{PbI}_{2}-\mathrm{BBF}$ composite, respectively. All the characteristic ${ }^{1} \mathrm{H},{ }^{19} \mathrm{~F}$, and ${ }^{11} \mathrm{~B}$ peaks of $\mathrm{BFF}$ in $\mathrm{PbI}_{2}-\mathrm{BBF}$ composite show an obvious shift to higher $\delta$ value in comparison to pure BBF. The shift of ${ }^{1} \mathrm{H}$ is obvious in the magnified spectra in Fig. S5, and this shift is ascribed to the interaction between the $\mathrm{N}-\mathrm{H}$ bonds in $\mathrm{BBF}$ and $\mathrm{I}$ ions of $\mathrm{PbI}_{2}$ [29]. The shift of ${ }^{19} \mathrm{~F}$ is due to the interaction between $\mathrm{F}$ and $\mathrm{Pb}$, where the valence electron deviates from the proton, and the shielding effect is weakened, so the signal peak appears in the low field. Meanwhile, the interaction force induces a decrease of the electron cloud density around $\mathrm{F}$ and an enhancement of the de-shielding effect, which leads to the shift of ${ }^{11} \mathrm{~B}$ NMR peak to higher $\delta$ value. All these interactions between $\mathrm{BBF}$ and perovskite precursor will retard the crystallization process of perovskite film, as described in Fig. 1a, which is beneficial to promoting the quality of the perovskite film [30]. 

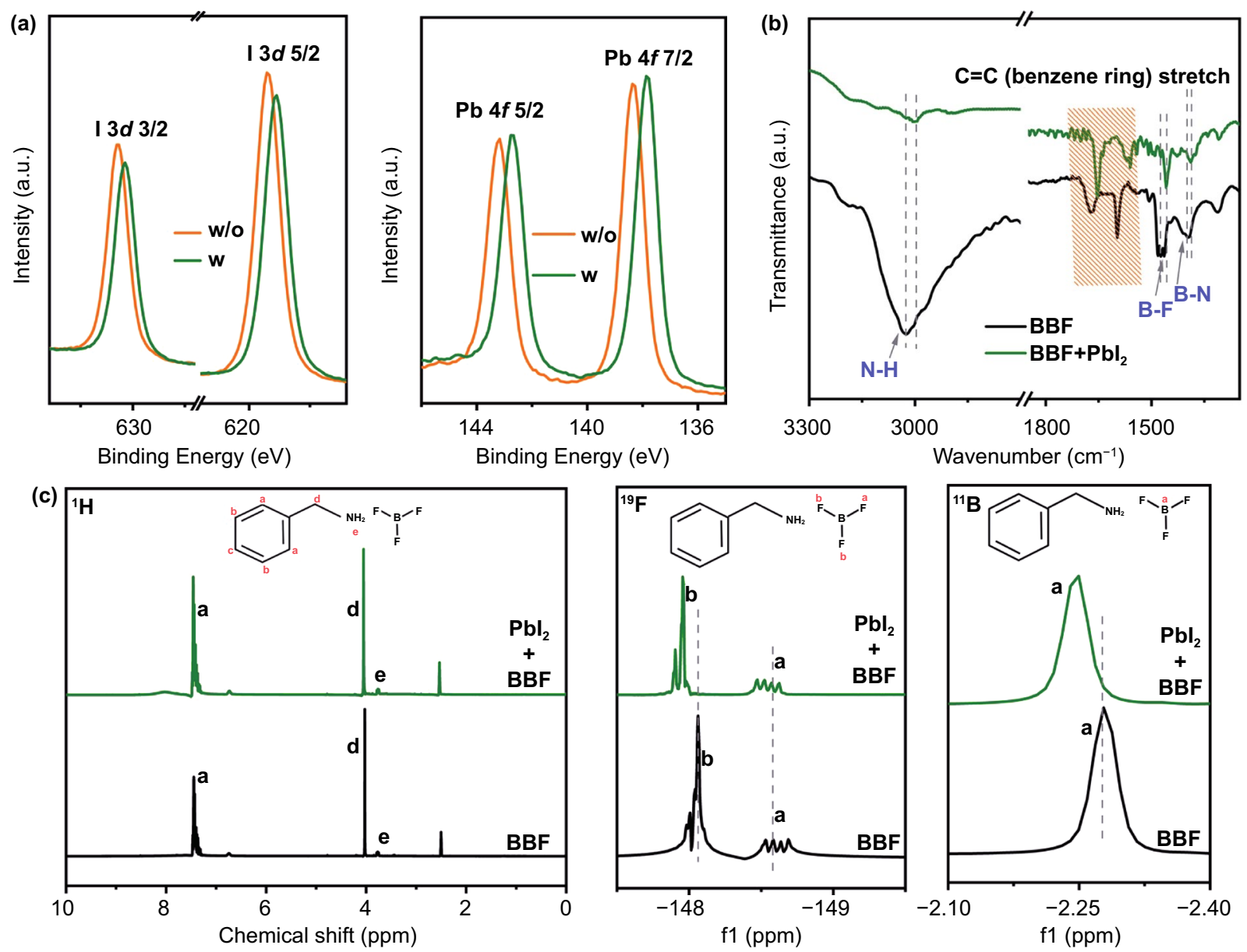

Fig. 3 a I $3 \mathrm{~d}$ and $\mathrm{Pb} 4 \mathrm{f}$ XPS spectra of the perovskite film with and without BBF additive. b FTIR spectra of BBF solution with and without $\mathrm{PbI}_{2} \cdot \mathrm{c}^{1} \mathrm{H},{ }^{19} \mathrm{~F},{ }^{11} \mathrm{~B}$ NMR of BBF solution with and without $\mathrm{PbI}_{2}$

\subsection{Modification Effect of BBF on Perovskite Film}

Then, the influence of BBF additives on the morphology and crystallinity of perovskite films was characterized by scanning electron microscopy (SEM), atom force microscopy (AFM), and X-ray diffraction (XRD). As shown in Fig. 4a, $\mathrm{b}$, all the perovskite films with and without BBF additives show smooth surfaces, and the average roughness $\left(R_{a}\right)$ of the perovskite film with an optimal BBF additive concentration $\left(1.5 \mathrm{mg} \mathrm{mL}^{-1}\right.$ ) is about $\sim 17 \mathrm{~nm}$, which is only $5 \mathrm{~nm}$ less than that of the control film. However, all the films show different grain sizes, and in order to more intuitively perceive the change of the grain size, a statistical analysis of grain size distribution is obtained from SEM images (Fig. 4c). For the control film, the grain size ranges from 200 to $1290 \mathrm{~nm}$ with an average grain size of $597 \mathrm{~nm}$, which is consistent with the result reported by us earlier [31]. The grain size of the perovskite film improves with the increase of BBF additive concentration. When the additive concentration reaches $1.5 \mathrm{mg} \mathrm{mL}^{-1}$, the grain size of the perovskite is maximum, with the largest grain of $\sim 5.8 \mu \mathrm{m}$ and average size of $2.89 \mu \mathrm{m}$, which is about $\sim 6$ times larger than that of the control film. However, the grain size decreases when the concentration of additive increases to $2.0 \mathrm{mg} \mathrm{mL}^{-1}$, possibly because excessive BBF in the precursor solution affects the Gibbs free energy of nucleation of the perovskite grain [32]. Figure S6 depicts the cross-sectional SEM images of perovskite films without and with optimized BBF additive. The control film exhibits clear grain boundaries and small grain size $(\sim 500 \mathrm{~nm})$, while the perovskite film with BBF additive is an aggregate of compact and large grains and has almost no grain boundaries. The SEM results indicate that 
(a)

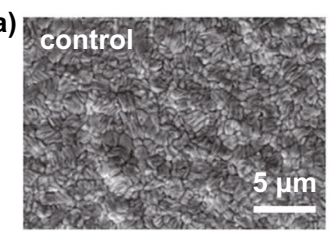

(b)
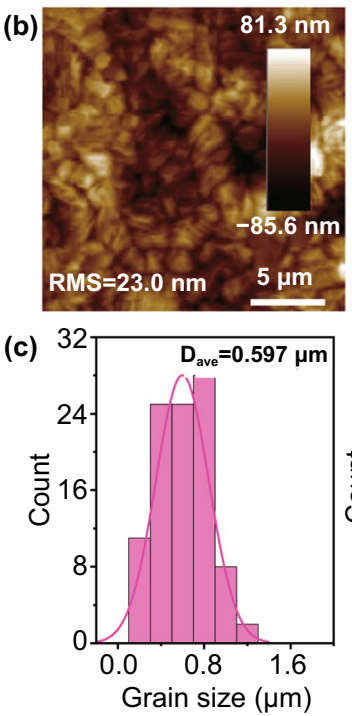

(d)

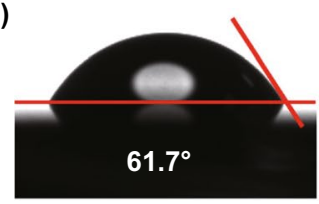

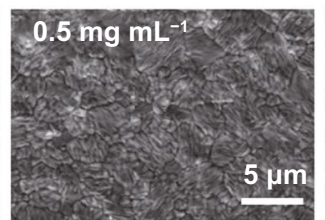
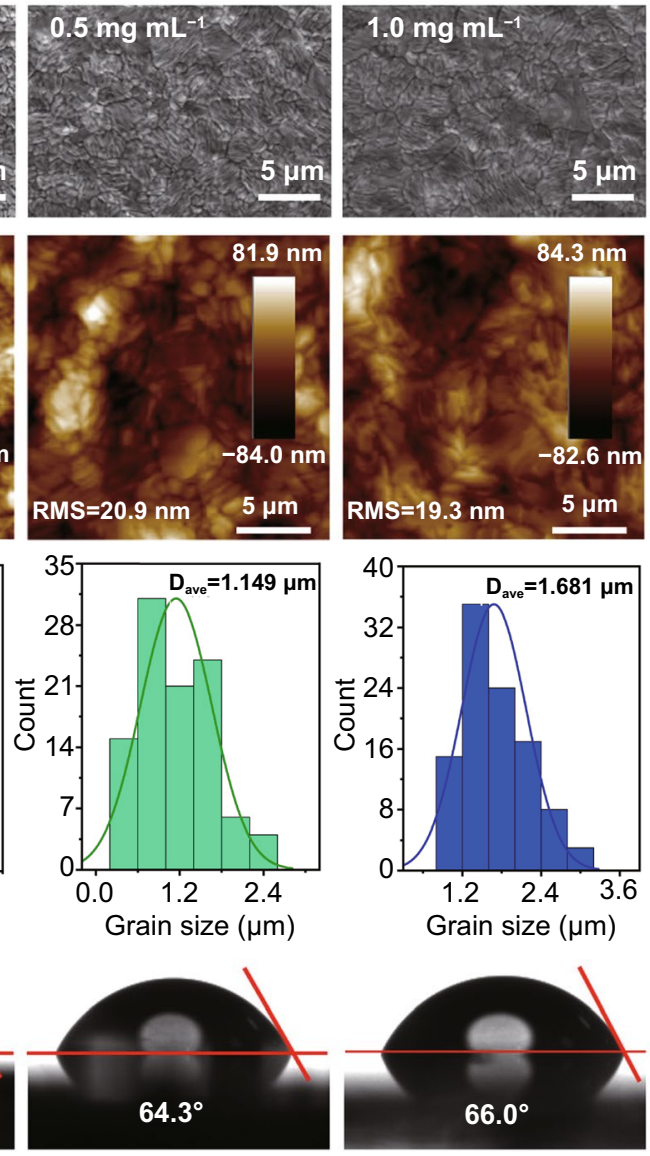
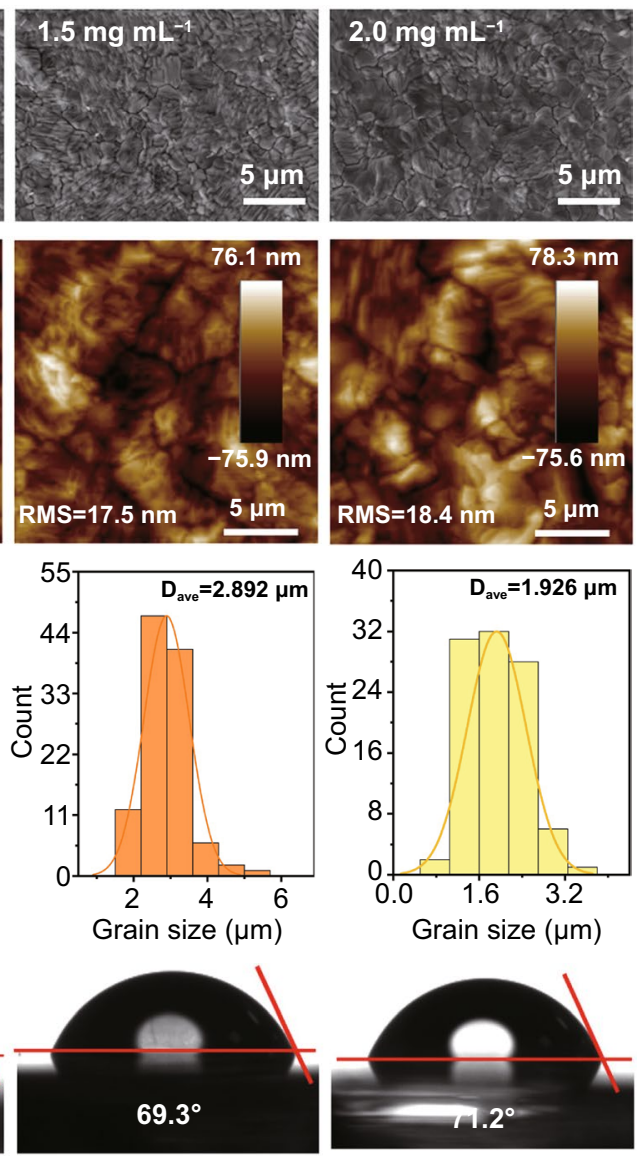

Fig. 4 a Top-view SEM images. b AFM images. $\mathbf{c}$ grain size distributions. d contact angles of perovskite films with different concentrations of $\mathrm{BBF}$ additives

BBF can simultaneously affect the crystallinity and density of the perovskite film. As shown in Fig. S7, XRD patterns of the perovskite films with and without BBF are similar and match with the typical black phase perovskite peak, with the diffraction peaks at $14.1^{\circ}, 28.2^{\circ}$, and $31.6^{\circ}$ corresponding to (001), (002), and (012) crystal planes of tetragonal FAMAPbI $_{3}$. When the concentration of BBF additive is $1.5 \mathrm{mg} \mathrm{mL}^{-1}$, the intensity of the reflection peak reaches a maximum, while the full width at half maximum (FWHM) of the (001) plane achieves a minimum value. The diffraction peaks of all the perovskite films have no movement, indicating that $\mathrm{BBF}$ is not doped into the crystal lattice, but rather exists on the boundary or the surface of the film. Then, the distribution of BBF in perovskite film is detected by time of flight secondary ion mass spectroscopy (ToF-SIMS) (Fig. S8). It is interesting to find that $\mathrm{C}_{7} \mathrm{H}_{9} \mathrm{~N}$ in $\mathrm{BBF}$ is mainly distributed on the surface of the perovskite, while $\mathrm{BF}_{3}$ in $\mathrm{BBF}$ shows an exponential decay in the perovskite film. This special distribution is beneficial to improving the hydrophobicity of the perovskite due to surface enrichment by fluorine and benzene groups, which is confirmed by the increase of deionized water contact angle of the perovskite films with the increase of additive concentration, and this increased hydrophobicity benefits the stability of the perovskite film.

To gain insight into the quality of the perovskite films and charge-carrier kinetics, including the effect of BBF concentrations on the photo-excited charge-carrier transport behavior from the perovskite layer to Spiro-OMeTAD, the steady-state PL and time-resolved PL (TRPL) are measured. As shown in Fig. 5a-c, all of the perovskite films exhibit a strong luminescence characteristic peak at $\sim 800 \mathrm{~nm}$, which is consistent with the absorption edge of $\mathrm{FAMAPbI}_{3}$ perovskite [33]. The perovskite film with optimized BBF additive exhibits the highest emission intensity, which indicates high crystal quality, as confirmed in the SEM and XRD results, and a low nonradiative recombination. The TRPL decay 
(a)

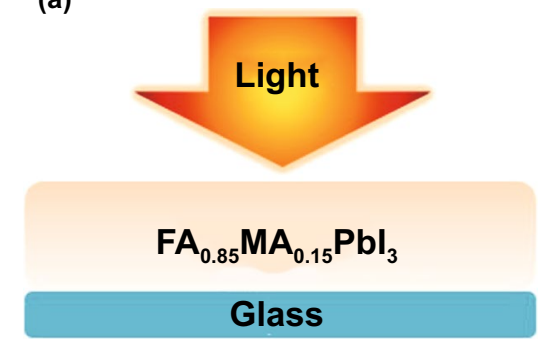

(d)

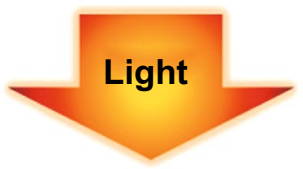

Spiro-OMeTAD

$\mathrm{FA}_{0.85} \mathrm{MA}_{0.15} \mathrm{Pbl}_{3}$

Glass
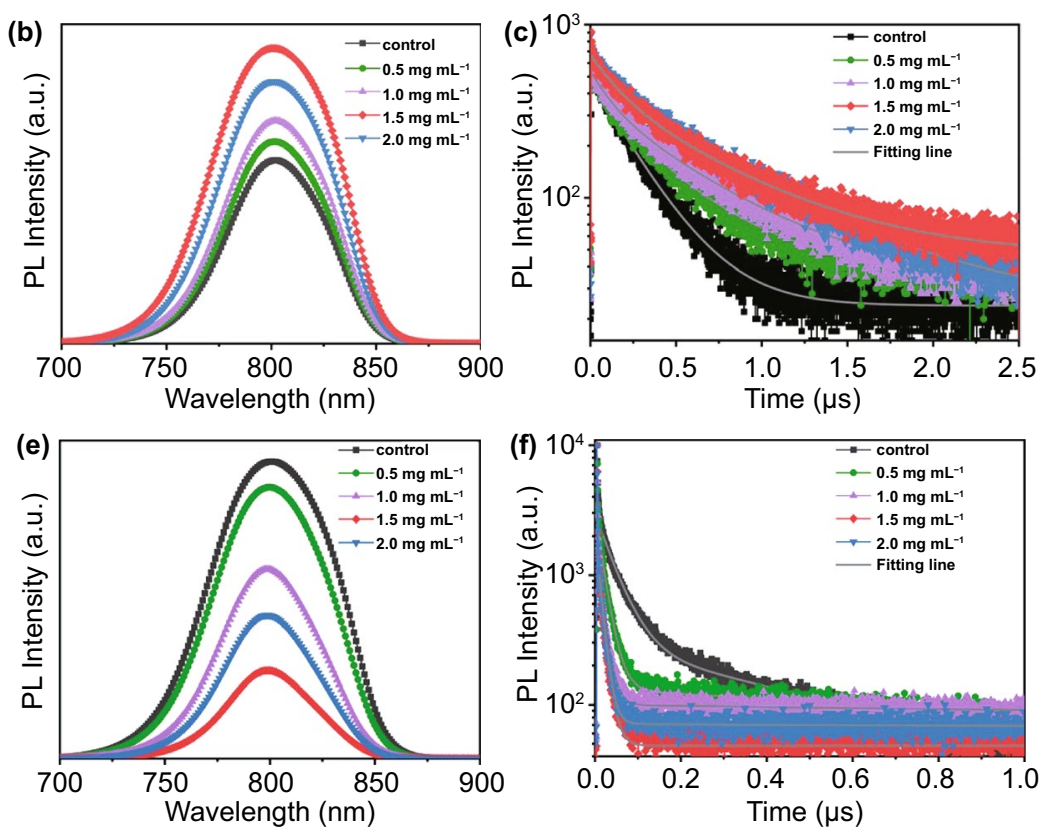

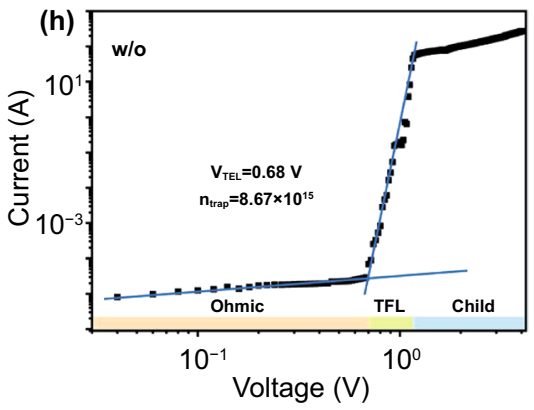

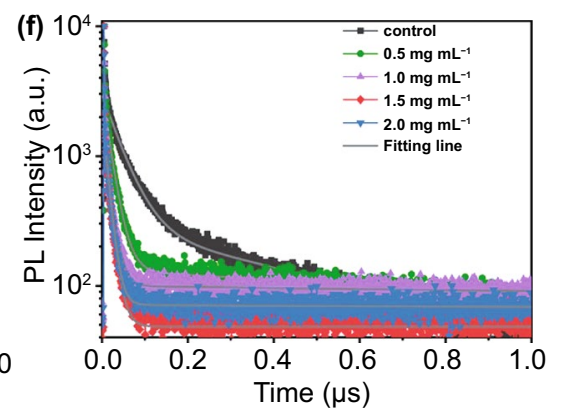

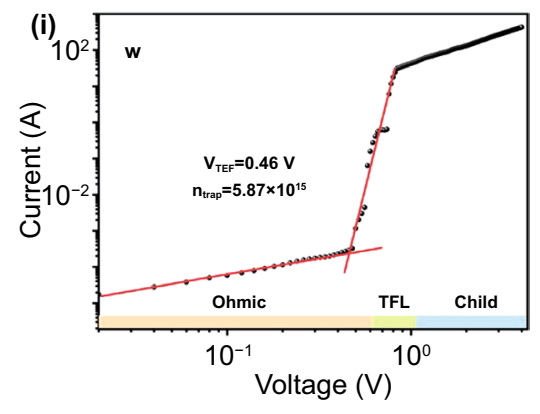

(g)

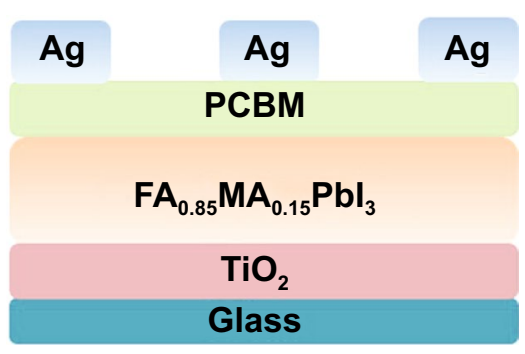

Fig. 5 a Schematic of film architecture (perovskite/glass) for PL measurements. b Steady-state PL spectra and $\mathbf{c}$ PL decay curves of perovskite films with and without BBF additive. d Schematic of film architecture (Spiro-OMeTAD/perovskite/glass) for PL measurements. e Steady-state $\mathrm{PL}$ spectra and $\mathbf{f} \mathrm{PL}$ decay curves of Spiro-OMeTAD/perovskite/glass. The space-charge-limited current versus voltage of $\mathbf{g}$ devices $\left(\mathrm{FTO} / \mathrm{TiO}{ }_{2} /\right.$ perovskite/PCBM/Ag) fabricated $\mathbf{h}$ without and $\mathbf{i}$ with $\mathrm{BBF}$ additive

parameters listed in Table $\mathrm{S} 1$ are fitted by the bi-exponential decay function $\mathrm{f}(\mathrm{t})=\mathrm{A}_{1} \exp \left(-\mathrm{t} / \tau_{1}\right)+\mathrm{A}_{2} \exp \left(-\mathrm{t} / \tau_{2}\right)[34,35]$, where $A_{1}$ and $A_{2}$ are the corresponding decay amplitudes, and $\tau_{1}$ and $\tau_{2}$ are the fast and slow decay times, respectively. As expected, the average carrier lifetime $\left(\tau_{\text {ave }}\right)$ has increased by two times from 242.63 to $676.66 \mathrm{~ns}$ with optimized BBF additive, confirming that the $\mathrm{BBF}$ treatment can decrease the trap-assisted recombination.

Figure 5d-f exhibits the steady-state PL and TRPL decay for the perovskite/Spiro-OMeTAD films. The perovskite films with BBF additive show faster PL quenching and shorter carrier lifetime than the control device. The TRPL curves are also fitted by the bi-exponential decay function $f(t)=A_{1} \exp \left(-t / \tau_{1}\right)+A_{2} \exp \left(-t / \tau_{2}\right)$, and the fitted data are listed in Table S2. $\tau_{1}$ and $\tau_{2}$ are dominated by carrier transfer at the perovskite/Spiro-OMeTAD interface and radiative recombination of trapped charges from the bulk perovskite, respectively [36]. The fitted data establish that the BBF additives can both improve carrier transfer at the interface and reduce nonradiative recombination in the perovskite, which may be due to the gradient distribution of BBF that can adjust the surface band structure of the perovskite [37, 38].

The space-charge-limited current (SCLC) technique is conducted to quantitatively estimate the defect density in the perovskite using a device structure of $\mathrm{FTO} / \mathrm{TiO}_{2} /$ perovskite/PCBM/Ag (Fig. 5i-g). The trap-filled limit voltage $\left(\mathrm{V}_{\mathrm{TFL}}\right)$ and calculated trap density of the perovskite film with BBF additive are $0.45 \mathrm{~V}$ and $5.87 \times 10^{15} \mathrm{~cm}^{-3}$, respectively, 
which are lower than those of the control film $(0.68 \mathrm{~V}$ and $8.67 \times 10^{15} \mathrm{~cm}^{-3}$ ). The reduced trap density is accredited to the high quality of the perovskite film with good passivation and high crystallinity.

\subsection{Performance of Devices with BBF Additive}

To investigate the influence of BBF additive on the photovoltaic performance of PSCs, a typical planar-structured PSC is fabricated (Fig. 6a). Ultraviolet photoemission spectroscopy (UPS) is conducted to explore the effect of BBF additive on the energy band characters of the perovskite films. The band gap of the perovskite film is almost unchanged after the addition of BBF, as confirmed by the absorption (Fig. S9) and PL emission (Fig. 5b) spectra. As shown in Figs. 6b and $\mathrm{S} 10$, the BBF additive causes both the valence band maximum and conduction band minimum of the perovskite to move up, which can reduce the energy barrier and loss for hole transfer from the perovskite to Spiro-OMeTAD while blocking the electrons from moving to the Spiro-OMeTAD for reducing the interface recombination [39].

Figure $6 \mathrm{c}$ depicts the $J-V$ characteristics of the planar PSCs with different concentrations of BBF additives, and Table 1 exhibits their photovoltaic parameters. It is quite obvious that the PSC with optimized BBF additive $\left(1.5 \mathrm{mg} \mathrm{mL}^{-1}\right)$ delivers a champion photovoltaic performance with a short-circuit current density $\left(J_{s c}\right)$ of $25.33 \mathrm{~mA} \mathrm{~cm}^{-2}$, an open-circuit voltage $\left(V_{o c}\right)$ of $1.14 \mathrm{~V}$, and a fill-factor $(\mathrm{FF})$ of 0.81 , achieving a PCE up to $23.24 \%$. In contrast, the control PSC has a relatively inferior performance with a $J_{s c}$ of $25.35 \mathrm{~mA} \mathrm{~cm}^{-2}$, (a)

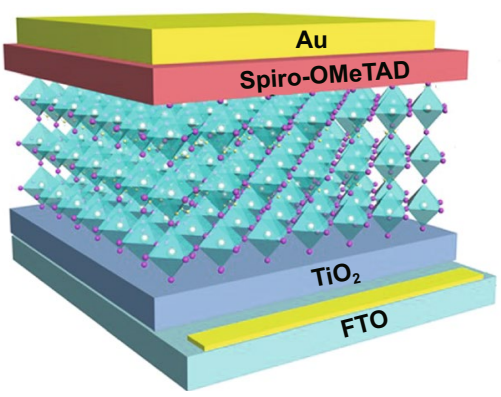

(d)
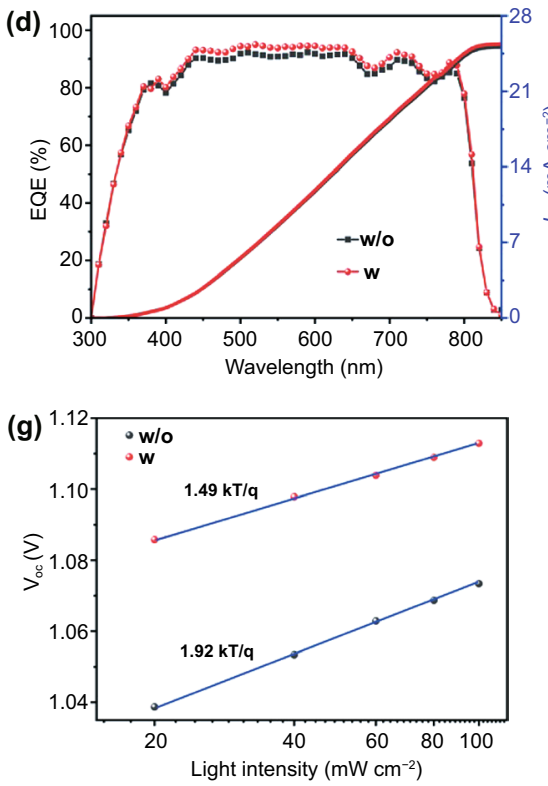

(b)
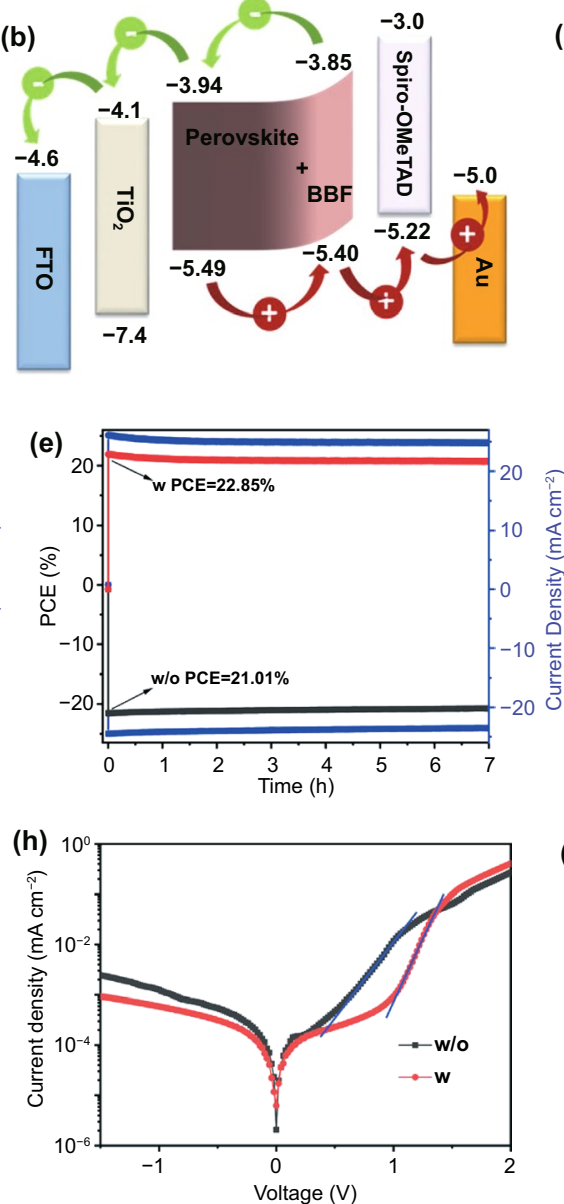
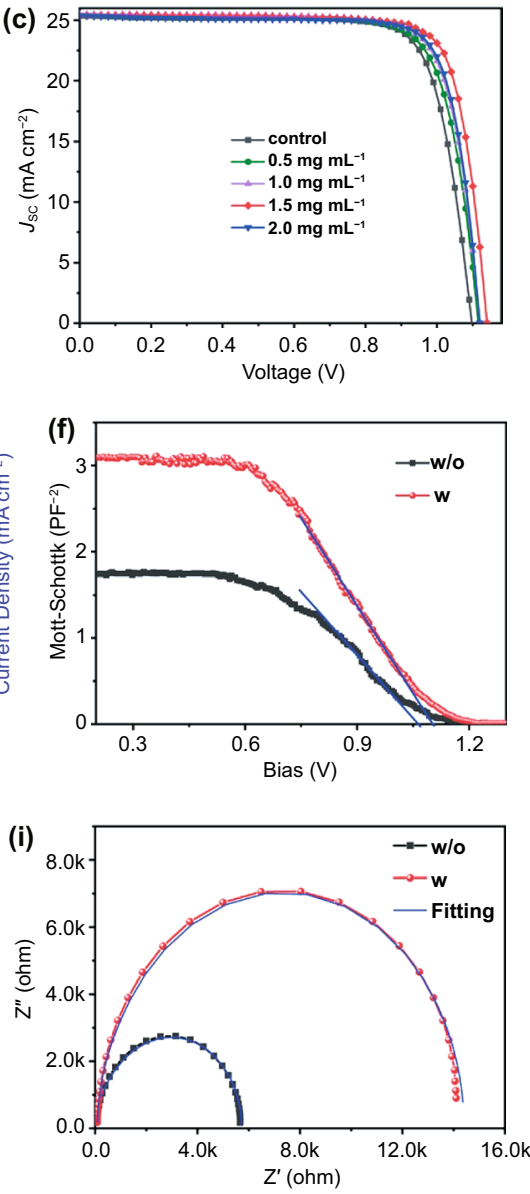

Fig. 6 a Schematic image of the hybrid PSC device with the structure FTO/TiO 2 /perovskite/Spiro-OMeTAD/Au. b Schematic energy-level alignment of the hybrid PSCs with BBF additive. $\mathbf{c} J-V$ curves of the hybrid PSCs with different concentrations of BBF additive. d EQE spectra. e stable output. f Mott-Schottky plots. $\mathbf{g} V_{O C}$ dependence on light intensity. $\mathbf{h}$ dark current-voltage characteristic and i Nyquist plots of the hybrid PSCs with and without BBF additive 
Table 1 Summary of the photovoltaic parameters of the hybrid PSCs with different concentrations of BBF additives

\begin{tabular}{lllll}
\hline $\begin{array}{l}\text { Devices } \\
\left(\mathrm{mg} \mathrm{mL}^{-1}\right)\end{array}$ & $V_{O C}(\mathrm{~V})$ & $J_{S C}\left(\mathrm{~mA} \mathrm{~cm}^{-2}\right)$ & FF & PCE $(\%)$ \\
\hline control & 1.10 & 25.35 & 0.77 & 21.60 \\
0.5 & 1.11 & 25.33 & 0.78 & 22.03 \\
1.0 & 1.12 & 25.38 & 0.79 & 22.32 \\
1.5 & 1.14 & 25.33 & 0.81 & 23.24 \\
2.0 & 1.12 & 25.36 & 0.80 & 22.65 \\
\hline
\end{tabular}

a $V_{o c}$ of 1.10, and a FF of 0.77 , resulting in a PCE of $21.6 \%$. According to the photovoltaic data, the $V_{o c}$ and FF increase obviously, which is attributed to a suitable band alignment between the perovskite with BBF and the Spiro-OMeTAD. $J_{s c}$ remains almost unchanged with the addition of BBF, and the values are confirmed by the EQE spectra (Fig. 6d). The integrated $J_{s c}$ values of the devices with and without BBF additive are 25.33 and $25.35 \mathrm{~mA} \mathrm{~cm}^{-2}$, respectively, which match well with the values obtained from the $J$ - $V$ curves in Fig. 6c. As shown in Fig. S11 and Table S3, the device with BBF additive displays similar $J$ - $V$ curves under forward and backward scanning, showing a small hysteresis index (HI) of 2.4\%, whereas the HI for the control device is $12.1 \%$. The much smaller hysteresis factor for the optimized device is attributed to the efficient charge extraction and transport at the perovskite interface. The steady-state current densities at the maximum power points of the PSCs are measured for $7 \mathrm{~h}$ (Fig. 6e). The stabilized PCE for the control device is $21.01 \%$, whereas that of the device with BBF additive is $22.85 \%$. To determine the reproducibility of the PSCs, 30 distinct devices are fabricated using the same procedure, with the statistical photovoltaic parameters presented in Fig. S12. All the key parameters exhibit fairly narrow distributions, indicating that all the devices have good reproducibility.

The surface-accumulated BBF can change the band structure of the underlying perovskite film, which will influence the built-in potential $\left(V_{b i}\right)$ of the PSCs [30]. The $V_{b i}$ of devices is assessed via a capacitance versus voltage (MottSchottky) analysis. As shown in Fig. 6f, the PSC with BBF additive displays a higher $V_{b i}(1.11 \mathrm{~V})$ than the control PSC $(1.07 \mathrm{~V})$. The improved $V_{b i}$ benefits the $V_{o c}$ of PSCs and assists in charge transport and collection. To gain insight into the recombination kinetics within PSCs, the $V_{o c}$ versus light intensity of the device is measured and presented in Fig. 6g.
According to the literature [40], when the slope of the line strays from $1 \mathrm{kT} \mathrm{q}^{-1}$, it reveals trap-assisted recombination. The slope of the line decreases from 1.92 to $1.49 \mathrm{kT} \mathrm{q}^{-1}$ with the addition of BBF, which suggests a more effective suppression of trap-assisted charge recombination in the optimized device and is consistent with the TRPL and SCLC results. The dark $J-V$ curves of PSCs are also measured and shown in Fig. 6h. By fitting the curves with an equivalent circuit of a Shockley diode [41], it is found that the device with BBF additive possesses better diode behavior, showing relatively smaller saturation current $\left(9.49 \times 10^{-10} \mathrm{~mA} \mathrm{~cm}^{-2}\right)$ than the control device $\left(2.60 \times 10^{-9} \mathrm{~mA} \mathrm{~cm}^{-2}\right)$, indicating suppressed charge recombination with a higher rectification ratio and higher $V_{o c}$ in the device with BBF additive [42].

Electrochemical impedance spectroscopy (EIS) is conducted to further elucidate the positive effect of BBF additive on the charge transport properties of the PSCs. Nyquist plots of devices without and with BBF additive are shown in Fig. 6i, and the fitted results are listed in Table S4. The device with BBF additive exhibits lower series resistance $\left(R_{S}\right)$ and higher recombination resistance $\left(R_{\text {rec }}\right)$ compared with the control device, indicating optimized charge transport and suppressed charge recombination [43, 44].

\subsection{Effect of BBF on the Stability of Device}

Besides the high photovoltaic parameters, stability is another important metric for PSCs. Therefore, the air stability of perovskite devices is examined. As shown in Fig. 7a, when the unencapsulated PSCs without and with BBF additive are stored in air under relative humidity of $\approx 25 \%$ at $25{ }^{\circ} \mathrm{C}$ for $2880 \mathrm{~h}$, the BBF-treated device demonstrates superior stability, maintaining $91 \%$ of its initial efficiency, whereas the PCEs of the control PSCs devices drop to $58 \%$ of their initial values during the same period. After aging, the perovskite layers were characterized by XRD measurement, and, as shown in Fig. $7 b$, the $\delta$-phase and $\mathrm{PbI}_{2}$ can be observed in the control perovskite film, which means that the control perovskite not only partially changes from $\alpha$-phase to $\delta$-phase, but also partially decomposed into $\mathrm{PbI}_{2}$ and MAI. The peak intensity ratio of the $\mathrm{PbI}_{2}$ to (100) diffraction peak of the perovskite is 0.33 , which is much higher than that of the perovskite film with BBF additive (0.13). Meanwhile, there is no $\delta$-phase in the aged perovskite film with BBF additive. Therefore, the 

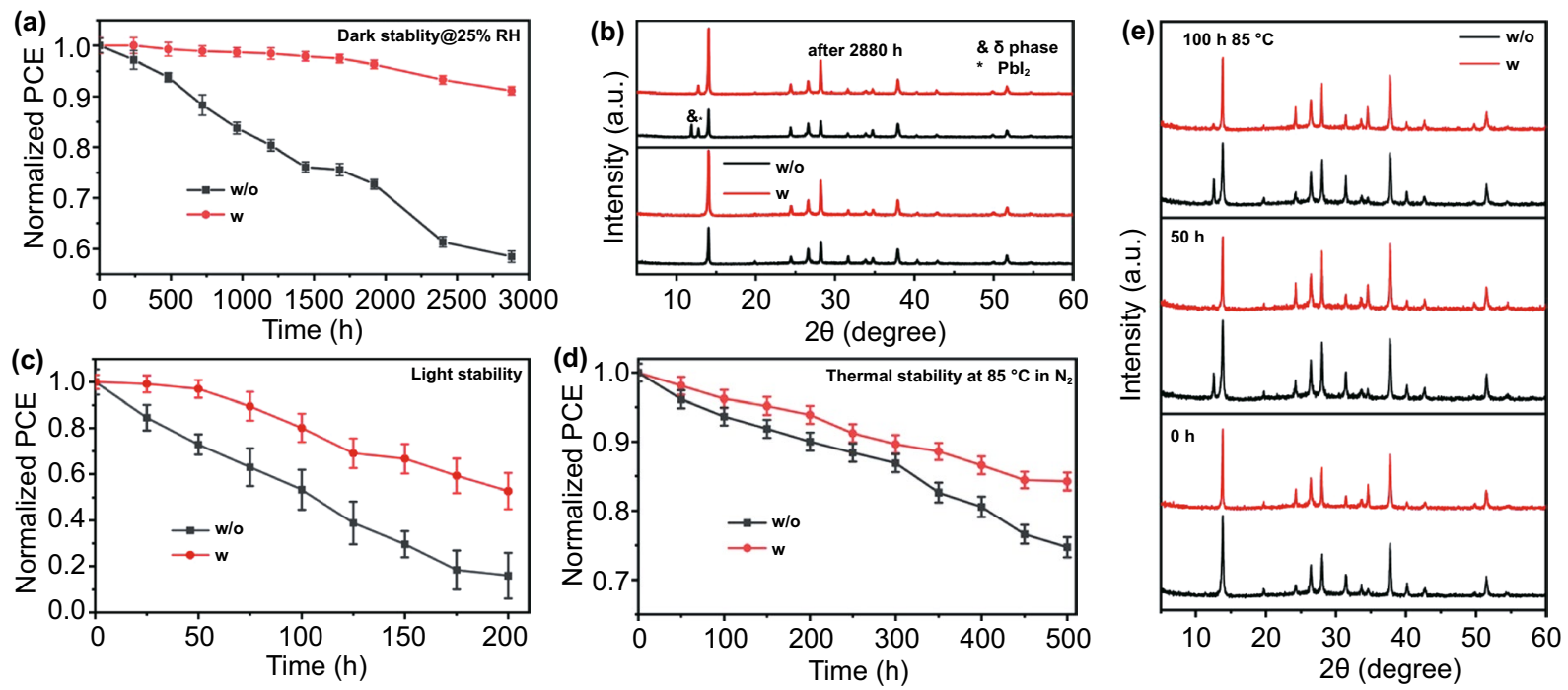

Fig. 7 a Air stability (humidity: $\approx 25 \%$ ). b XRD pattern of the hybrid PSCs with and without BBF additive after aging in air for 2880 h. $\mathbf{c}$ Light stability and $\mathbf{d}$ thermal stability ( $\mathrm{T}: \approx 85{ }^{\circ} \mathrm{C}$ in $\mathrm{N}_{2}$ atmosphere) of the PSCs with and without BBF additive. e XRD patterns of the perovskite films with and without $\mathrm{BBF}$ additive after aging at $85^{\circ} \mathrm{C}$ in $\mathrm{N}_{2}$ atmosphere for $50 \mathrm{~h}$ and $100 \mathrm{~h}$

BBF can effectively enhance the stability of the perovskite film through reducing the phase transition and decomposition, which can be ascribed to the passivation effect and hydrophobicity of BBF, which could effectively reduce the defect density and water/oxygen adsorption and thus stabilize the perovskite lattice.

Additionally, the effect of BBF additive on the light and thermal stabilities of PSCs is also evaluated. As shown in Fig. 7c, when the devices are illuminated under one-sun equivalent intensity for $200 \mathrm{~h}$, the PCE of the control PSC decreases to $16 \%$ of its initial value, while the device with $\mathrm{BBF}$ additive retains $53 \%$ of its initial value. For testing thermal stability, the devices are annealed at $85^{\circ} \mathrm{C}$ in a $\mathrm{N}_{2}$-filled glove box, and the PCE of the devices with BBF remains at $84 \%$ of its initial value for $500 \mathrm{~h}$, whereas the PCE of the control device decreases to $74 \%$ of its initial value during the same period (Fig. 7d). Then, the perovskite layers that aged for 50 and $100 \mathrm{~h}$ are measured by XRD. As shown in Fig. 7e, it is noted that the perovskite film with BBF additive shows much lower $\mathrm{PbI}_{2}$ diffraction peaks and higher perovskite diffraction peaks than those of the control film after $100 \mathrm{~h}$ of thermal annealing. The improvement of thermal stability is ascribed to heavy hydrogen bonding between the BBF and perovskite, which reduces the release or decomposition of cations in the perovskite under thermal stress.

\section{Conclusions}

In summary, we demonstrate a facile way to effectively passivate perovskite film by using a multifunctional molecule (BBF) containing both $\mathrm{C}_{7} \mathrm{H}_{9} \mathrm{~N}$ and $\mathrm{BF}_{3}$ groups as additive. It is interesting to find that $\mathrm{C}_{7} \mathrm{H}_{9} \mathrm{~N}$ mainly distributes on the surface of the perovskite, while $\mathrm{BF}_{3}$ shows an exponential decay in the perovskite film. This special distribution of BBF, which has different coordination ability with perovskite cations and anions, serves multiple functions: it can retard the crystallization process leading to high-quality perovskite film, associate with undercoordinated cations and anions for defect passivation, adjust the surface electronic properties of perovskite forming an energy cascade layer to promote charge transport, as well as increase hydrophobicity of the perovskite film to improve the ambient stability of the perovskite. Relying on the synergistic benefits of the above functions, the BBF-incorporated devices based on the FAMAPbI $_{3}$ absorber deliver a high PCE of $23.24 \%$ and high ambient and light illumination stability. The new multifunctional additive (BBF) has the potential to be widely used in low-band-gap perovskites for more efficient perovskite devices.

Acknowledgements The authors acknowledge support from the National Natural Science Foundation of China (62074095/61704101/91733301), the National Key Research 
and Development Program of China (2016YFA0202403), the Fundamental Research Funds for the Central Universities GK (201903048), the 111 Project (Grant No. B21005), the Fundament Research Funds for the Central University (2019TS004), and DNL Cooperation Fund CAS (DNL180311).

Open Access This article is licensed under a Creative Commons Attribution 4.0 International License, which permits use, sharing, adaptation, distribution and reproduction in any medium or format, as long as you give appropriate credit to the original author(s) and the source, provide a link to the Creative Commons licence, and indicate if changes were made. The images or other third party material in this article are included in the article's Creative Commons licence, unless indicated otherwise in a credit line to the material. If material is not included in the article's Creative Commons licence and your intended use is not permitted by statutory regulation or exceeds the permitted use, you will need to obtain permission directly from the copyright holder. To view a copy of this licence, visit http://creativecommons.org/licenses/by/4.0/.

Supplementary Information The online version contains supplementary material available at https://doi.org/10.1007/ s40820-021-00688-2.

\section{References}

1. Best Research-Cell Efficiency Chart. https://www.nrel.gov/ pv/cell-efficiency.html (accessed 03/2021)

2. J. Chen, N.G. Park, Causes and solutions of recombination in perovskite solar cells. Adv. Mater. 31, 1803019 (2019). https:// doi.org/10.1002/adma.201803019

3. W. Tress, N. Marinova, O. Inganäs, M.K. Nazeeruddin, S.M. Zakeeruddin et al., Predicting the open-circuit voltage of $\mathrm{CH}_{3} \mathrm{NH}_{3} \mathrm{PbI}_{3}$ perovskite solar cells using electroluminescence and photovoltaic quantum efficiency spectra: the role of radiative and non-radiative recombination. Adv. Energy Mater. 5, 1400812 (2015). https://doi.org/10.1002/aenm.2014008

4. J. Xue, R. Wang, Y. Yang, The surface of halide perovskites from nano to bulk. Nat. Rev. Maters. 5, 809 (2020). https:// doi.org/10.1038/s41578-020-0221-1

5. R. Xia, X.X. Gao, Y. Zhang, N. Drigo, V.I.E. Queloz et al., An efficient approach to fabricate air-stable perovskite solar cells via addition of a self-polymerizing ionic liquid. Adv. Mater. 32, 2003801 (2020). https://doi.org/10.1002/adma.202003801

6. T.S. Su, F.T. Eickemeyer, M.A. Hope, F. Jahanbakhshi, M. Mladenovic et al., Crown ether modulation enables over $23 \%$ efficient formamidinium-based perovskite solar cells. J. Am. Chem. Soc. 142, 19980 (2020). https://doi.org/10.1021/jacs. 0c08592

7. B. Li, Y. Zhang, L. Fu, T. Yu, S. Zhou et al., Surface passivation engineering strategy to fully-inorganic cubic $\mathrm{CsPbI}$ perovskites for high-performance solar cells. Nat. Commun. 9, 1076 (2018). https://doi.org/10.1038/s41467-018-03169-0
8. F. Li, X. Deng, F. Qi, Z. Li, D. Liu et al., Regulating surface termination for efficient inverted perovskite solar cells with greater than 23\% efficiency. J. Am. Chem. Soc. 142, 20134 (2020). https://doi.org/10.1021/jacs.0c09845

9. N. Liu, C. Yam, First-principles study of intrinsic defects in formamidinium lead triiodide perovskite solar cell absorbers. Phys. Chem. Chem. Phys. 20, 6800 (2018). https://doi.org/10. 1039/C8CP00280K

10. Q. Jiang, Y. Zhao, X. Zhang, X. Yang, Y. Chen et al., Surface passivation of perovskite film for efficient solar cells. Nat. Photonics 13, 460 (2019). https://doi.org/10.1038/ s41566-019-0398-2

11. J. Xia, C. Liang, S. Mei, H. Gu, B. He et al., Deep surface passivation for efficient and hydrophobic perovskite solar cells. J. Mater. Chem. A 9, 2919 (2021). https://doi.org/10.1039/ D0TA10535J

12. S. Tan, I. Yavuz, M.H. Weber, T. Huang, C.-H. Chen et al., Shallow iodine defects accelerate the degradation of $\alpha$-phase formamidinium perovskite. Joule 4, 2426 (2020). https://doi. org/10.1016/j.joule.2020.08.016

13. S. Yuan, F. Qian, S. Yang, Y. Cai, Q. Wang et al., NbF5: a novel $\alpha$-phase stabilizer for FA-based perovskite solar cells with high efficiency. Adv. Funct. Mater. 29, 1807850 (2019). https://doi.org/10.1002/adfm.201807850

14. F. Qian, S. Yuan, Y. Cai, Y. Han, H. Zhao et al., Novel surface passivation for stable FA0.85MA0.15PbI3 perovskite solar cells with $21.6 \%$ efficiency. Sol. RRL 3, 1900072 (2019). https://doi.org/10.1002/solr.201900072

15. B. Chen, P.N. Rudd, S. Yang, Y. Yuan, J. Huang, Imperfections and their passivation in halide perovskite solar cells. Chem. Soc. Rev. 48, 3842 (2019). https://doi.org/10.1039/C8CS0 $0853 \mathrm{~A}$

16. J. Zhang, Z. Jin, L. Liang, H. Wang, D. Bai et al., Iodineoptimized interface for inorganic $\mathrm{CsPbI}_{2} \mathrm{Br}$ perovskite solar cell to attain high stabilized efficiency exceeding $14 \%$. Adv. Sci. 5, 1801123 (2018). https://doi.org/10.1002/advs.20180 1123

17. Y. Cai, J. Cui, M. Chen, M. Zhang, Y. Han et al., Multifunctional enhancement for highly stable and efficient perovskite solar cells. Adv. Funct. Mater. 31, 2005776 (2020). https://doi. org/10.1002/adfm.202005776

18. Y. Yang, J. Wu, X. Wang, Q. Guo, X. Liu et al., Suppressing vacancy defects and grain boundaries via ostwald ripening for high-performance and stable perovskite solar cells. Adv. Mater. 32, 1904347 (2020). https://doi.org/10.1002/adma. 201904347

19. L.-L. Jiang, Z.-K. Wang, M. Li, C.-C. Zhang, Q.-Q. Ye et al., Suppressing vacancy defects and grain boundaries via ostwald ripening for high-performance and stable perovskite solar cells. Adv. Funct. Mater. 28, 1705875 (2018). https://doi.org/ 10.1002/adma.201904347

20. K. Zhang, Z. Wang, G. Wang, J. Wang, Y. Li et al., A prenucleation strategy for ambient fabrication of perovskite solar cells with high device performance uniformity. Nat. Commun. 11, 1006 (2020). https://doi.org/10.1038/s41467-020-14715-0 
21. R. Wang, J. Xue, K.-L. Wang, Z.-K. Wang, Y. Luo et al., Constructive molecular configurations for surface-defect passivation of perovskite photovoltaics. Science 366, 1509 (2019). http://science.sciencemag.org/content/366/6472/1509

22. N. Li, S. Tao, Y. Chen, X. Niu, C.K. Onwudinanti et al., Cation and anion immobilization through chemical bonding enhancement with fluorides for stable halide perovskite solar cells. Nat. Energy 4, 408 (2019). https://doi.org/10.1038/ s41560-019-0382-6

23. Y. Lv, H. Zhang, J. Wang, L. Chen, L. Bian et al., All-in-one deposition to synergistically manipulate perovskite growth for high-performance solar cell. Research 2020, 1 (2020). https:// doi.org/10.34133/2020/2763409

24. F. Wang, W. Geng, Y. Zhou, H.-H. Fang, C.-J. Tong et al., Phenylalkylamine passivation of organolead halide perovskites enabling high-efficiency and air-stable photovoltaic cells. Adv. Mater. 28, 9986 (2016). https://doi.org/10.1002/adma.20160 3062

25. A. Abate, M. Saliba, D.J. Hollman, S.D. Stranks, K. Wojciechowski et al., Supramolecular halogen bond passivation of organic-inorganic halide perovskite solar cells. Nano Lett. 14, 3247 (2014). https://doi.org/10.1021/n1500627x

26. Z. Fang, W. Chen, Y. Shi, J. Zhao, S. Chu et al., Dual passivation of perovskite defects for light-emitting diodes with external quantum efficiency exceeding 20\%. Adv. Funct. Mater. 30, 1909754 (2020). https://doi.org/10.1002/adfm.201909754

27. H. Zhu, Y. Ren, L. Pan, O. Ouellette, F.T. Eickemeyer et al., Synergistic effect of fluorinated passivator and hole transport dopant enables stable perovskite solar cells with an efficiency near 24\%. J. Am. Chem. Soc. 143, 3231 (2021). https://doi. org/10.1021/jacs.0c12802

28. B. Li, C. Fei, K. Zheng, X. Qu, T. Pullerits et al., Constructing water-resistant $\mathrm{CH} 3 \mathrm{NH} 3 \mathrm{PbI} 3$ perovskite films via coordination interaction. J. Mater. Chem. A 4, 17018 (2016). https:// doi.org/10.1039/C6TA06892H

29. X. Shi, Y. Wu, J. Chen, M. Cai, Y. Yang et al., Thermally stable perovskite solar cells with efficiency over $21 \%$ via a bifunctional additive. J. Mater. Chem. A 8, 7205 (2020). https://doi.org/10.1039/D0TA01255F

30. H. Li, G. Wu, W. Li, Y. Zhang, Z. Liu et al., Additive engineering to grow micron-sized grains for stable high efficiency perovskite solar cells. Adv. Sci. 6, 1901241 (2019). https://doi. org/10.1002/advs.201901241

31. S. Yuan, Y. Cai, S. Yang, H. Zhao, F. Qian et al., Simultaneous cesium and acetate coalloying improves efficiency and stability of $\mathrm{FA}_{0.85} \mathrm{MA}_{0.15} \mathrm{PbI}_{3}$ perovskite solar cell with an efficiency of $21.95 \%$. Sol. RRL 3, 1900220 (2019). https://doi.org/10. 1002/solr.201900220

32. J.-W. Lee, S.-H. Bae, Y.-T. Hsieh, N. De Marco, M. Wang et al., A bifunctional lewis base additive for microscopic homogeneity in perovskite solar cells. Chem 3, 290 (2017). https://doi.org/10.1016/j.chempr.2017.05.020

33. T. Wu, Y. Wang, X. Li, Y. Wu, X. Meng et al., Efficient defect passivation for perovskite solar cells by controlling the electron density distribution of donor- $\pi$-acceptor molecules. Adv. Energy Mater. 9, 1803766 (2019). https://doi.org/10. 1002/aenm.201803766

34. S. Yang, W. Liu, Y. Han, Z. Liu, W. Zhao et al., $2 \mathrm{D} \mathrm{Cs}{ }_{2} \mathrm{PbI}_{2} \mathrm{Cl}_{2}$ nanosheets for holistic passivation of inorganic $\mathrm{CsPbI}_{2} \mathrm{Br}$ perovskite solar cells for improved efficiency and stability. Adv. Energy Mater. 10, 2002882 (2020). https://doi.org/10.1002/ aenm.202002882

35. C. Duan, J. Cui, M. Zhang, Y. Han, S. Yang et al., Precursor engineering for ambient-compatible antisolvent-free fabrication of high-efficiency $\mathrm{CsPbI} 2 \mathrm{Br}$ perovskite solar cells. Adv. Energy Mater. 10, 2000691 (2020). https://doi.org/10.1002/ aenm.202000691

36. J.-S. Yeo, R. Kang, S. Lee, Y.-J. Jeon, N. Myoung et al., Precursor engineering for ambient-compatible antisolvent-free fabrication of high-efficiency $\mathrm{CsPbI}_{2} \mathrm{Br}$ perovskite solar cells. Nano Energy 12, 96 (2015). https://doi.org/10.1002/aenm. 202000691

37. M. Saba, M. Cadelano, D. Marongiu, F. Chen, V. Sarritzu et al., Correlated electron-hole plasma in organometal perovskites. Nat. Commun. 5, 5049 (2014). https://doi.org/10.1038/ ncomms6049

38. K.-L. Wang, X.-M. Li, Y.-H. Lou, M. Li, Z.-K. Wang, $\mathrm{CsPbrI}_{2}$ perovskites with low energy loss for high-performance indoor and outdoor photovoltaics. Sci. Bull. 66, 347 (2021). https://doi.org/10.1016/j.scib.2020.09.017

39. J.M. Ball, A. Petrozza, Defects in perovskite-halides and their effects in solar cells. Nat. Energy 1, 16149 (2016). https://doi. org/10.1038/nenergy.2016.149

40. X. Zheng, B. Chen, J. Dai, Y. Fang, Y. Bai et al., Defect passivation in hybrid perovskite solar cells using quaternary ammonium halide anions and cations. Nat. Energy 2, 17102 (2017). https://doi.org/10.1038/nenergy.2017.102

41. J.W. Lee, Z. Dai, C. Lee, H.M. Lee, T.H. Han et al., Tuning molecular interactions for highly reproducible and efficient formamidinium perovskite solar cells via adduct approach. J. Am. Chem. Soc. 140, 6317 (2018). https://doi.org/10.1021/ jacs.8b01037

42. K. Chen, J. Wu, Y. Wang, Q. Guo, Q. Chen et al., Defect passivation by alcohol-soluble small molecules for efficient $\mathrm{p}-\mathrm{i}-\mathrm{n}$ planar perovskite solar cells with high open-circuit voltage. J. Mater. Chem. A 7, 21140 (2019). https://doi.org/10.1039/ C9TA06718C

43. J.A. Christians, P.A. Miranda Herrera, P.V. Kamat, Transformation of the excited state and photovoltaic efficiency of $\mathrm{CH}_{3} \mathrm{NH}_{3} \mathrm{PbI}_{3}$ perovskite upon controlled exposure to humidified air. J. Am. Chem. Soc. 137, 1530 (2015). https://doi.org/ 10.1021/ja511132a

44. J. Xue, R. Wang, K.-L. Wang, Z.-K. Wang, I. Yavuz et al., Crystalline liquid-like behavior: surface-induced secondary grain growth of photovoltaic perovskite thin film. J. Am. Chem. Soc. 141, 13948 (2019). https://doi.org/10.1021/jacs. 9b06940 